\title{
AÇÃO DO POLIETILENO GLICOL NA GERMINAÇÃO DE SEMENTES DE Adenanthera pavonina L. E O USO DE POLIAMINAS NA ATENUAÇÃO DO ESTRESSE HÍDRICO SOB DIFERENTES TEMPERATURAS ${ }^{1}$
}

\author{
SAMARA CAMARGO LOPES FONSECA², SONIA CRISTINA JULIANO GUALTIERI DE ANDRADE PEREZ ${ }^{3}$
}

\begin{abstract}
RESUMO - O presente trabalho teve como objetivo avaliar a porcentagem e a velocidade de germinação de sementes de Adenanthera pavonina L., previamente escarificadas com ácido sulfúrico, submetidas às soluções de polietileno glicol nos potenciais osmóticos de 0,$0 ;-0,1 ;-0,2$; $-0,3 ;-0,4 ;-0,5 \mathrm{MPa}$ e colocadas para germinar a 25,30 e $35^{\circ} \mathrm{C}$, observando, posteriormente, a atenuação do estresse hídrico induzido pela adição de poliaminas (100ppm) às soluções de polietileno glicol. O aumento da concentração de polietileno glicol no meio germinativo acarretou decréscimo na porcentagem e na velocidade de germinação das sementes, mesmo com a adição de poliaminas às soluções. A atenuação do estresse hídrico foi obtida em sementes submetidas às soluções acrescidas de poliaminas, devido ao significativo aumento na porcentagem de germinação dessas sementes; entretanto não houve ampliação do limite máximo de tolerância ao polietileno glicol.
\end{abstract}

Termos para indexação: polietileno glicol, putrescina, espermidina, temperatura, Adenanthera pavonina.

\section{GERMINATION OF Adenanthera pavonina L. SEEDS: PEG AND POLYAMINES EFFECTS UNDER DIFFERENT TEMPERATURES}

\begin{abstract}
This study was carried out to observe PEG effects on germination and polyamines effects on attenuation of PEG stress under different temperatures. Adenanthera pavonina seeds were quimically scarified with $\mathrm{H}_{2} \mathrm{SO}_{4}$ for 20 minutes and washed in distilled water. The experiments were conducted with solutions of polyetilene glycol at six concentrations $(0,0 ;-0,1 ;-0,2 ;-0,3$; $-0,4 ;-0,5 \mathrm{MPa})$. Later, solutions of putrescine $(100 \mathrm{ppm})$ and espermidine $(100 \mathrm{ppm})$ were used at the same potentials. The tests were conducted at temperatures of 25,30 and $35^{\circ} \mathrm{C}$. A significant reduction in the germinability and rate were observed when PEG concentrations, with polyamines, were increased. Polyamines atenuated hydric stress in all potentials; it increased the seed germinability.

Index terms: polyetilene glycol, putrescine, espermidine, temperature, Adenanthera pavonina.
\end{abstract}

\section{INTRODUÇÃO}

O processo germinativo se inicia com a absorção de água por embebição, porém, há necessidade de que a semente alcance um nível adequado de hidratação o qual permita a reativação dos seus processos metabólicos. Uma análise das relações hídricas das taxas de germinação de sementes revelou que o início da germinação está relacionado com a sensi-

\footnotetext{
${ }^{1}$ Aceito para publicação em 03.01.2003: parte da dissertação de Mestrado do primeiro autor no Curso de Pós-Graduação em Ecologia e Recursos Naturais, Universidade Federal de São Carlos; bolsista CAPES.

${ }^{2}$ Bióloga, doutoranda do Depto. de Produção Vegetal - ESALQ/USP; Rua
}

bilidade da iniciação do crescimento radicular ao conteúdo de água do meio, considerando a habilidade do embrião em absorver água do meio e iniciar seu crescimento dependente do potencial osmótico de suas células. O acúmulo de solutos antes do crescimento radicular diminui o potencial osmótico, gerando pressão de turgescência suficiente para permitir que o embrião rompa a barreira do tegumento. Durante o processo germinativo a água atua como um agente estimulador e

Antonio Gaiola, 560 apto. 604, Boa Vista, 13465-000, Americana, SP; email:saejoe@uol.com.br

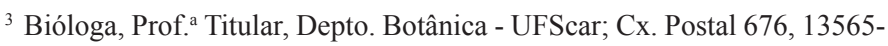
905, São Carlos, SP. 
controlador, uma vez que, além de promover o amolecimento do tegumento, favorecendo a penetração do oxigênio, e aumentar o volume do embrião e dos tecidos de reserva, estimula as atividades metabólicas básicas, favorecendo o crescimento do eixo embrionário (Marcos Filho, 1986).

Potenciais hídricos negativos, especialmente no começo da embebição, inviabilizam a sequência dos eventos germinativos da semente durante a absorção de água (Bansal et al, 1980; citados por Hebling, 1997). Por outro lado, de acordo com Borges \& Rena (1993), o excesso de umidade ocasiona um decréscimo na germinação, visto que impede a penetração do oxigênio e reduz todo o processo metabólico resultante.

Com relação à temperatura, seus efeitos podem ser avaliados a partir de mudanças ocasionadas na porcentagem e na velocidade de germinação, afetando, segundo Carvalho \& Nakagawa (1988), as reações bioquímicas que determinam o processo germinativo. Para a maioria das espécies a temperatura ótima de germinação, na qual a maior germinabilidade é alcançada em menor tempo (Mayer \& Poljakoff-Mayber, 1989), encontra-se entre 15 e $30^{\circ} \mathrm{C}$; a máxima varia entre 35 e $40^{\circ} \mathrm{C}$, podendo a mínima chegar ao ponto de congelamento. De maneira geral, temperaturas sub-ótimas reduzem a velocidade de germinação, resultando em alteração da uniformidade de emergência, provavelmente em razão do aumento do tempo de exposição ao ataque de patógenos. Por outro lado, temperaturas supra-ótimas aumentam a velocidade de germinação, embora somente as sementes mais vigorosas consigam germinar (Carvalho \& Nakagawa, 1988).

Villanueva \& Huang (1993), citados por Hebling, (1997), relatam que, em sementes, durante o período de quebra de dormência tardio e no início do processo de embebição, as concentrações de poliaminas aumentam e ficam semelhantes às concentrações de RNA, DNA e proteínas, sugerindo que estas estão envolvidas nos primeiros estágios da germinação e podem ser essenciais à esse processo. As poliaminas, particularmente a putrescina, podem ter um papel na manutenção do $\mathrm{pH}$ intracelular; durante a germinação de sementes, a larga escala de hidrólise de macromoléculas no endosperma pode causar um desbalanço na concentração de $\mathrm{H}^{+}$intracelular e, o concomitante acúmulo de putrescina pode ser um mecanismo compensatório para a manutenção do $\mathrm{pH}$ intracelular. Já a espermidina é considerada como um regulador de crescimento de plantas atuando na divisão e na diferenciação celular (Galston \& Kaursawhney, 1987).

A espécie arbórea Adenanthera pavonina L., pertencente à família Fabaceae e subfamília Mimosoideae, é nativa da
Ásia tropical, sendo popularmente conhecida como olho-dedragão. Por apresentar crescimento rápido, conforme citado por Fanti (1997), esta espécie serve como bom dossel para plantas herbáceas, arbustivas e trepadeiras que não toleram altas intensidades luminosas. O cerne vermelho desta árvore é usado como um substituto da madeira do sândalo vermelho (Pterocarpus sandalinus L.), sendo assim, importante fonte fornecedora de madeira de boa qualidade para construções. Além de ser utilizada em reflorestamentos, como planta ornamental e como forrageira na Tailândia, o cozimento das sementes e da madeira permite o seu uso no tratamento de infecções pulmonares, podendo também o produto ser aplicado externamente no tratamento da oftalmia crônica (Baburaj \& Gunasekaran, 1993, citados por Fanti, 1997).

Devido à possibilidade de múltiplos usos que a espécie Adenanthera pavonina apresenta, e estando adaptada a diferentes condições de clima e de solo, este trabalho se propôs a avaliar os efeitos específicos do PEG (polietileno glicol 6000) na germinação, observando, posteriormente, a atenuação do estresse hídrico induzido com a adição de poliaminas às soluções, nos mesmos potenciais osmóticos, em temperaturas sub-ótima, ótima e supra-ótima de germinação.

\section{MATERIAL E MÉTODOS}

O presente trabalho foi conduzido no Laboratório de Ecofisiologia de Germinação de Sementes pertencente ao Departamento de Botânica da Universidade Federal de São Carlos, S.P durante o período de setembro/1997 a abril/1998. As sementes de Adenanthera pavonina L. foram provenientes do Instituto de Pesquisa e Estudos Florestais de Piracicaba (I.P.E.F./ ESALQ/ USP), em julho de 1997, apresentando teor de água de $12 \%$. As sementes foram armazenadas em recipientes de vidro com tampas plásticas, contendo no fundo sílicagel encoberta com papel de filtro e conservadas em geladeira; mantiveram, assim, seu grau de umidade até o início do experimento.

As sementes foram previamente escarificadas com ácido sulfúrico concentrado por 20 minutos (Zpevak \& Perez, 1993), lavadas em água corrente, banhadas em solução de hipoclorito de sódio (2\%) durante uma hora, lavadas em água destilada, sendo, posteriormente, secas em papel toalha e incubadas em placas de Petri de $15 \mathrm{~cm}$ de diâmetro, forradas com duas folhas de papel de filtro umedecidas com $10 \mathrm{ml}$ da "solução-teste" acrescidas de Captan 0,2\%; as placas "controle" foram umedecidas somente com solução de Captan $0,2 \%$. A germinação foi avaliada em soluções puras de PEG 
6000 preparadas de acordo com as especificações contidas na tabela citada por Villela et al. (1992) e colocadas para germinar em câmara climática tipo B.O.D. (precisão de $\pm 0,5^{\circ} \mathrm{C}$ ) nas temperaturas de 25,30 e $35^{\circ} \mathrm{C}$. Posteriormente, as sementes foram submetidas às soluções mistas $\mathrm{PEG}+$ putrescina (100ppm) e PEG + espermidina (100ppm) nos potenciais de 0,$0 ;-0,1,-0,2,-0,3,-0,4$ e $-0,5 \mathrm{MPa}$ e colocadas para germinar nas mesmas temperaturas.

As contagens das sementes germinadas para cálculo de velocidade e de porcentagem de germinação foram realizadas diariamente, sendo consideradas germinadas as que apresentaram extensão radicular igual ou maior que $2 \mathrm{~mm}$ e curvatura geotrópica positiva. Como as sementes utilizadas são fotoblásticas neutras (Fanti, 1997), as luzes da incubadora permaneceram apagadas durante os experimentos e as sementes só receberam luz por ocasião da realização das contagens. Os experimentos foram finalizados quando todas as sementes germinaram ou quando as remanescentes nas placas apresentaram-se mortas. Adotou-se como critério de limite máximo de tolerância, o intervalo entre a concentração máxima em que ocorreu a germinação e a concentração subsequente, em que sementes não germinaram ou apresentaram-se deterioradas.

Os experimentos foram realizados com quatro repetições de 50 sementes em cada tratamento; o delineamento experimental adotado foi inteiramente casualizado, sendo as comparações dos valores médios de porcentagem e da velocidade de germinação feitas através da aplicação de análise de variância simples (Anova) e, para a verificação da ação das soluções puras e mistas de polietileno glicol, independente do potencial osmótico usado, de dupla entrada (cinco potenciais $\mathrm{x}$ três tratamentos). Os valores de porcentagem de germinação foram transformados, de acordo com Snedecor \& Cochran (1978), em valor angular (arco seno $\left.\sqrt{x}_{\mathrm{x}} / 100\right)$ e as médias, comparadas pelo teste de Tukey a 5\% de significância.

\section{RESULTADOS E DISCUSSÃO}

A Tabela 1 mostra os valores médios de porcentagem e de velocidade de germinação de sementes, colocadas para germinar a $25^{\circ} \mathrm{C}$, submetidas a diferentes concentrações de PEG, de $\mathrm{PEG}+$ putrescina e de PEG + espermidina. Houve redução gradual da velocidade e da porcentagem de germinação à medida que o potencial osmótico das soluções tornou-se mais negativo. As porcentagens de germinação das sementes tratadas com as soluções de PEG e de PEG + poliaminas diferiram estatisticamente da porcentagem de germinação encontrada no experimento controle, indicando sensibilidade das sementes ao polietileno glicol e às poliaminas. As sementes germinaram até o potencial osmótico de -0,4MPa, implicando um limite de tolerância das sementes entre -0,4 e $-0,5 \mathrm{MPa}$. Sementes tratadas com soluções mistas de PEG + espermidina apresentaram maior porcentagem de germinação do que as sementes tratadas com soluções de PEG e soluções mistas de PEG + putrescina, porém os limites máximos de tolerância das sementes permaneceram constantes.

Os valores médios de porcentagem e de velocidade de germinação das sementes colocadas para germinar sob temperatura ótima, submetidas as soluções puras e mistas de PEG, são apresentados na Tabela 2. As porcentagens de germina-

TABELA 1. Valores médios para porcentagem (G\%) e velocidade de germinação de sementes de Adenanthera pavonina colocadas para germinar a $25^{\circ} \mathrm{C}$, tratadas com soluções de polietileno glicol e com soluções mistas de polietileno glicol+poliaminas.

\begin{tabular}{|c|c|c|c|c|c|c|}
\hline \multirow{2}{*}{$\begin{array}{c}\text { Potenciais } \\
\text { osmóticos } \\
(\mathrm{MPa})\end{array}$} & \multicolumn{2}{|c|}{ PEG } & \multicolumn{2}{|c|}{ PEG + putrescina } & \multicolumn{2}{|c|}{ PEG + espermidina } \\
\hline & G\% & $\begin{array}{c}\text { Velocidade } \\
\left(\operatorname{dias}^{-1}\right)\end{array}$ & G\% & $\begin{array}{c}\text { Velocidade } \\
\left(\operatorname{dias}^{-1}\right)\end{array}$ & $\mathrm{G} \%$ & $\begin{array}{l}\text { Velocidade } \\
\left(\text { dias }^{-1}\right)\end{array}$ \\
\hline Controle & $81 \mathrm{a}$ & $0,215 \mathrm{a}$ & $81 \mathrm{a}$ & $0,215 \mathrm{a}$ & $81 \mathrm{a}$ & $0,215 \mathrm{a}$ \\
\hline$-0,1$ & $58 \mathrm{~b}$ & $0,144 \mathrm{~b}$ & $59 \mathrm{~b}$ & $0,147 \quad b$ & $61 \mathrm{~b}$ & $0,148 \quad b$ \\
\hline$-0,2$ & $42 \mathrm{c}$ & $0,142 \quad b$ & $47 \mathrm{c}$ & $0,142 \quad b$ & $49 \quad \mathrm{c}$ & 0,147 \\
\hline$-0,3$ & 33 & $0,139 \mathrm{~b}$ & 42 & 0,106 & 50 & 0,108 \\
\hline$-0,4$ & 22 & $0,090 \quad \mathrm{c}$ & 24 & $0,101 \quad \mathrm{c}$ & 29 & 0,095 \\
\hline $\mathrm{F}$ & 198,50 & 568,74 & 144,03 & 557,86 & 128,10 & 458,35 \\
\hline $\mathrm{Fc}$ & 3,80 & 3,80 & 3,80 & 3,80 & 3,80 & 3,80 \\
\hline D.M.S. & 3,85 & 0,005 & 4,07 & 0,007 & 4,23 & 0,007 \\
\hline $\mathrm{CV}(\%)$ & 4,12 & 3,80 & 4,17 & 2,74 & 4,28 & 3,10 \\
\hline
\end{tabular}

Valores médios seguidos pelas mesmas letras, na coluna, não diferem entre si pelo teste de Tukey a 5\% de significância. 
TABELA 2. Valores médios para porcentagem (G\%) e velocidade de germinação de sementes de Adenanthera pavonina colocadas para germinar a $30^{\circ} \mathrm{C}$, tratadas com soluções de polietileno glicol e com soluções mistas de polietileno glicol+poliaminas.

\begin{tabular}{|c|c|c|c|c|c|c|}
\hline \multirow{2}{*}{$\begin{array}{c}\text { Potenciais } \\
\text { osmóticos } \\
(\mathrm{MPa})\end{array}$} & \multicolumn{2}{|c|}{ PEG } & \multicolumn{2}{|c|}{ PEG + putrescina } & \multicolumn{2}{|c|}{ PEG + espermidina } \\
\hline & $\mathrm{G} \%$ & $\begin{array}{c}\text { Velocidade } \\
\left(\operatorname{dias}^{-1}\right)\end{array}$ & $\mathrm{G} \%$ & $\begin{array}{c}\text { Velocidade } \\
\left(\operatorname{dias}^{-1}\right)\end{array}$ & $\mathrm{G} \%$ & $\begin{array}{c}\text { Velocidade } \\
\left(\operatorname{dias}^{-1}\right)\end{array}$ \\
\hline Controle & $85 a$ & $0,216 \mathrm{a}$ & $85 a$ & $0,216 a$ & $85 a$ & $0,216 \mathrm{a}$ \\
\hline$-0,1$ & $57 \mathrm{~b}$ & $0,166 \mathrm{~b}$ & $64 \mathrm{~b}$ & $0,156 \mathrm{~b}$ & $67 \mathrm{~b}$ & $0,166 \mathrm{~b}$ \\
\hline$-0,2$ & $51 \quad \mathrm{c}$ & $0,149 \quad \mathrm{c}$ & $54 \mathrm{~b}$ & $0,153 \mathrm{~b}$ & $60 \mathrm{c}$ & $0,155 \quad \mathrm{c}$ \\
\hline$-0,3$ & $41 \quad \mathrm{~d}$ & $0,135 \quad \mathrm{c}$ & $44 \mathrm{bc}$ & $0,130 \quad \mathrm{c}$ & 49 & $0,151 \quad \mathrm{c}$ \\
\hline$-0,4$ & 24 & $0,113 \quad \mathrm{~d}$ & $30 \quad \mathrm{c}$ & $0,116 \quad \mathrm{c}$ & 32 & 0,104 \\
\hline $\mathrm{F}$ & 297,93 & 82,63 & 15,04 & 75,61 & 171,01 & 251,15 \\
\hline $\mathrm{Fc}$ & 3,80 & 3,80 & 3,80 & 3,80 & 3,80 & 3,80 \\
\hline D.M.S. & 3,91 & 0,015 & 18,34 & 0,015 & 4,55 & 0,01 \\
\hline $\mathrm{CV}(\%)$ & 3,79 & 5,44 & 17,34 & 5,76 & 4,05 & 3,38 \\
\hline
\end{tabular}

Valores médios seguidos pelas mesmas letras, na coluna, não diferem entre si pelo teste de Tukey a 5\% de significância.

ção em todos os potenciais osmóticos testados foram maiores do que as encontradas para sementes colocadas para germinar a $25^{\circ} \mathrm{C}$; as poliaminas utilizadas atenuaram a ação do polietileno glicol na germinação das sementes; não houve, porém, aumento dos limites máximos de tolerância.

Durante o procedimento experimental, as sementes colocadas em contato com as soluções aquosas, contendo solutos, iniciaram a embebição de água normalmente, cessando o processo assim que entraram em equilíbrio com o potencial osmótico da solução externa. Quando o potencial é suficientemente baixo, a expansão da raíz primária é impedida, além de, as sementes, contendo água suficiente para tornarem-se fisiologicamente ativas, mobilizarem reservas e iniciarem seu processo germinativo sem atingir a fase de alongamento celular, mesmo após algumas semanas de contato com a solução osmótica. Segundo Hadas (1976), citado por Hebling, (1997), mudanças no potencial hídrico externo produz um efeito nas propriedades hidráulicas do tegumento da semente, sendo que, quanto mais baixo for esse potencial, menor será o teor de água no tegumento e, consequentemente, a difusibilidade deste para a água. Isso retardará a absorção de água pela semente e o início da atividade enzimática, atrasando o desenvolvimento meristemático e a emergência da radícula.

Sementes incubadas a $35^{\circ} \mathrm{C}$ não germinaram, uma vez que foram colonizadas por fungos durante os dois primeiros dias de embebição.

As velocidades de germinação das sementes colocadas para germinar a 25 e $30^{\circ} \mathrm{C}$, tratadas com soluções puras e mistas de PEG apresentaram diferenças significativas entre o controle e todos os potenciais osmóticos testados (Tabelas 12), indicando sensibilidade das sementes a estes agentes osmóticos.

Os resultados de análise de variância para porcentagem e velocidade de germinação das sementes de A. pavonina, relacionando diferentes potenciais osmóticos e diferentes tratamentos com polietileno glicol e poliaminas, encontram-se nas Tabelas 3-6. Houve diferenças significativas entre os potenciais testados, independente dos agentes osmóticos utilizados, tanto na porcentagem como na velocidade de germinação das sementes (Tabelas 3 e 5). Constatou-se, também,

TABELA 3. Resultados da análise de variância para porcentagem e velocidade de germinação de sementes de Adenanthera pavonina, colocadas para germinar a $25^{\circ}$ C, em diferentes poten-ciais osmóticos, independentes dos agentes osmóticos utilizados.

\begin{tabular}{ccc}
\hline $\begin{array}{c}\text { Potenciais osmóticos } \\
(\mathrm{MPa})\end{array}$ & $\begin{array}{c}\% \\
\text { germinação }\end{array}$ & $\begin{array}{c}\text { Velocidade } \\
\left(\text { dias }^{-1}\right)\end{array}$ \\
\hline Controle & $81 \mathrm{a}$ & $0,215 \mathrm{a}$ \\
$-0,1$ & $59 \mathrm{~b}$ & $0,162 \mathrm{~b}$ \\
$-0,2$ & $46 \mathrm{c}$ & $0,152 \mathrm{~b}$ \\
$-0,3$ & $42 \mathrm{c}$ & $0,130 \quad \mathrm{c}$ \\
$-0,4$ & $25 \quad \mathrm{~d}$ & $0,110 \quad \mathrm{~d}$ \\
\hline F & 831,45 & 397,11 \\
Fc & 5,24 & 5,24 \\
D.M.S. & 4,14 & 0,011 \\
CV $(\%)$ & 6,95 & 2,00 \\
\hline
\end{tabular}

Valores médios seguidos pelas mesmas letras, na coluna, não diferem entre si pelo teste de Tukey a 5\% de significância. 
diferenças significativas entre os agentes osmóticos testados, independente dos potenciais, na porcentagem de germinação das sementes; não sendo constatadas diferenças significativas na velocidade de germinação (Tabelas 4 e 6). A Tabela 4 mostra estatisticamente a eficácia da espermidina sobre a putrescina na atenuação do estresse hídrico simulado; porém sob temperatura ótima, ambas mostraram-se eficazes (Tabela 6).

TABELA 4. Resultados da análise de variância para porcentagem e velocidade de germinação de sementes de Adenanthera pavonina, colocadas para germinar a $25^{\circ} \mathrm{C}$, submetidas a diferentes agentes osmóticos, independente dos potenciais utilizados.

\begin{tabular}{lcc}
\hline Agente osmótico & $\begin{array}{c}\% \\
\text { germinação }\end{array}$ & $\begin{array}{c}\text { Velocidade } \\
\left(\text { dias }^{-1}\right)\end{array}$ \\
\hline PEG & $47 \mathrm{~b}$ & $0,156 \mathrm{a}$ \\
PEG + putrescina & $51 \mathrm{~b}$ & $0,154 \mathrm{a}$ \\
PEG + espermidina & $54 \mathrm{a}$ & $0,153 \mathrm{a}$ \\
\hline F & 9,25 & 0,20 \\
Fc & 3,44 & 3,44 \\
D.M.S. & 3,51 & 0,01 \\
CV $(\%)$ & 6,95 & 2,0 \\
\hline
\end{tabular}

Valores médios seguidos pelas mesmas letras, na coluna, não diferem entre si pelo teste de Tukey a 5\% de significância

TABELA 5. Resultados da análise de variância para porcentagem e velocidade de germinação de sementes de Adenanthera pavonina, colocadas para germinar a $30^{\circ} \mathrm{C}$, em diferentes potenciais osmóticos, independentes dos agentes osmóticos utilizados.

\begin{tabular}{ccc}
\hline $\begin{array}{c}\text { Potenciais osmóticos } \\
(\mathrm{MPa})\end{array}$ & \% germinação & $\begin{array}{c}\text { Velocidade } \\
\left(\text { dias }^{-1}\right)\end{array}$ \\
\hline Controle & $85 \mathrm{a}$ & $0,216 \mathrm{a}$ \\
$-0,1$ & $64 \mathrm{~b}$ & $0,147 \mathrm{~b}$ \\
$-0,2$ & $55 \mathrm{c}$ & $0,145 \mathrm{~b}$ \\
$-0,3$ & $45 \quad \mathrm{~d}$ & $0,107 \quad \mathrm{c}$ \\
$-0,4$ & $28 \quad \mathrm{e}$ & $0,097 \quad \mathrm{~d}$ \\
\hline F & 446,81 & 10480,80 \\
Fc & 5,24 & 5,24 \\
D.M.S. & 5,70 & 0,002 \\
CV $(\%)$ & 8,75 & 1,5 \\
\hline
\end{tabular}

Valores médios seguidos pelas mesmas letras, na coluna, não diferem entre si pelo teste de Tukey a 5\% de significância.
TABELA 6. Resultados da análise de variância para porcentagem e velocidade de germinação de sementes de Adenanthera pavonina, colocadas para germinar a $30^{\circ} \mathrm{C}$, submetidas a diferentes agentes osmóticos, independente dos potenciais utilizados.

\begin{tabular}{lcl}
\hline Agente osmótico & $\begin{array}{c}\% \\
\text { germinação }\end{array}$ & $\begin{array}{c}\text { Velocidade } \\
\left(\text { dias }^{-1}\right)\end{array}$ \\
\hline PEG & $52 \mathrm{~b}$ & $0,142 \mathrm{a}$ \\
PEG + putrescina & $55 \mathrm{a}$ & $0,143 \mathrm{a}$ \\
PEG + espermidina & $59 \mathrm{a}$ & $0,142 \mathrm{a}$ \\
\hline F & 5,93 & 0,015 \\
Fc & 3,44 & 3,44 \\
D.M.S. & 4,83 & 0,002 \\
CV $(\%)$ & 6,75 & 1,5 \\
\hline
\end{tabular}

Valores médios seguidos pelas mesmas letras, na coluna, não diferem entre si pelo teste de Tukey a 5\% de significância

\section{CONCLUSÕES}

u Sementes colocadas para germinar a 25 e $30^{\circ} \mathrm{C}$ apresentaram limite máximo de tolerância às soluções de $\mathrm{PEG}$ e de $\mathrm{PEG}+$ poliaminas entre $-0,4$ e $-0,5 \mathrm{MPa}$;

u não houve aumento dos limites máximos de tolerância de sementes tratadas com soluções de PEG acrescidas de poliaminas;

u espermidina atenuou o estresse hídrico induzido sob temperatura sub-ótima;

u putrescina e espermidina atenuaram o estresse hídrico induzido sob temperatura ótima.

\section{REFERÊNCIAS}

BORGES, E.E.L.; RENA, A.B. Germinação de sementes. In: AGUIAR, I.B., PIÑA-RODRIGUES, F.C.M.; FIGLIOLIA, M.B. Sementes florestais tropicais. Brasília: Associação Brasileira de Tecnologia de Sementes, 1993. p.83-135.

CARVALHO, N.M.; NAKAGAWA, J. Sementes: ciência, tecnologia e produção. Campinas: Fundação Cargill, 1988. 424p.

FANTI, S.C. Comportamento germinativo sob condições de estresse e do sombreamento artificial e adubo químico na produção de mudas de Adenanthera pavonina L. 1997. 153f. Dissertação (Mestrado) - São Universidade Federal de São Carlos, São Carlos.

GALSTON, A.W.; KAURSAWHNEY, R. Polyamines as endogenous growth regulators. In: DAVIES, P.J. Plant hormones and their role in plant growth and development. New York: Martinus Nijhoff Publishers, 1987. 681p. 
HEBLING, S.A. Aspéctos ecofisiológicos da germinação de sementes de E. contortisiliquum (VELLOZO) MORONG. 1997. 143f. Tese (Doutorado) - Universidade Federal de São Carlos, São Carlos.

MARCOS FILHO, J. Germinação de sementes. In: CICERO, S.M.; MARCOS FILHO, J.; SILVA, W.R. (Coord.) Atualização em produção de sementes. Campinas: Fundação Cargill, p.11-39, 1986.

MAYER, A.M.; POLJAKOFF-MAYBER, A. The germination of seeds. 4.ed. Oxford: Pergamon , 1989. 270p.
SNEDECOR, G.W.; COCHRAN, W.G. Métodos estatísticos. México: Companhia Editorial Continental, 1978. 593p.

VILLELA, F.A.; FILHO, L.D.; SIQUEIRA, E.L. Tabela de potencial osmótico em função da concentração de polietileno glicol 6000 e da temperatura. Pesquisa Agropecuária Brasileira, Brasília, v.26, n.11/12, p.1957-1968, 1992.

ZPEVAK, F.A.; PEREZ, S.C.J.G.A. Efeitos da temperatura na germinação de sementes de Adenanthera pavonina L. Informativo ABRATES, Londrina, v.3, n.3, p.75, 1993. 